\title{
Evidence for a contact-based explanation of the own-age bias in face recognition
}

\author{
Virginia Harrison and Graham J. Hole \\ University of Sussex, Brighton, England
}

\begin{abstract}
Previous research has shown that we recognize faces similar in age to ourselves better than older or younger faces (e.g., Wright \& Stroud, 2002). This study investigated whether this own-age bias could be explained by the contact hypothesis used to account for the own-race bias (see Meissner \& Brigham, 2001). If the own-age bias stems from increased exposure to people of our own age, it should be reduced or absent in those with higher exposure to other age groups. Participants were asked to remember facial photographs of 8- to 11- and 20- to 25-year-olds. Undergraduates were faster and more accurate at recognizing faces of their own age. However, trainee teachers showed no such own-age bias; they recognized the children's faces more quickly than own-age faces and with comparable accuracy. These results support a contact-based explanation of the own-age bias.
\end{abstract}

Previous research suggests that young adults are better at recognizing faces and make more accurate eyewitness identifications than do older adults (e.g., Adams-Price, 1992; Searcy, Bartlett, \& Memon, 1999; Searcy, Bartlett, Memon, \& Swanson, 2001; Yarmey, 1993). Although cognitive performance deteriorates with age (see the review in Hedden \& Gabrieli, 2004), some of this apparent difference in facial memory performance might stem from the stimuli that are used: Typically, young adults (undergraduates) and older adults are compared on their ability to recognize young adult faces. Younger adults' superiority might therefore arise from an own-age face-processing bias.

Relatively little research has been performed on this topic, but the few studies that exist do appear to provide evidence for an own-age bias in face recognition. Wright and Stroud (2002) showed young and middle-aged adults videos of a "crime" in which the perpetrator was either similar or dissimilar in age to themselves. All the participants were more likely to correctly identify the perpetrator from a lineup of people belonging to their own age group, although further analysis revealed that this own-age identification advantage was significant only for the younger adults. Fulton and Bartlett (1991), using a between-subjects recognition paradigm, found that young adults were better at recognizing younger adult faces than older ones, whereas older adults' performance was similar for faces of all age groups.

Although these studies showed no own-age bias for older adult populations, others have done so. Using a paradigm to investigate unconscious transference, Perfect and Harris (2003) found that older adults were significantly more accurate at identifying perpetrators of a similar age to themselves than those of a younger age. Older adults were also more likely than younger adults to misidentify a bystander as the perpetrator of a crime when the lineup consisted of younger adults. This difference was eliminated when the lineup comprised older adults.

In addition to the forensic-style methodologies involving lineup procedures, the own-age bias has been investigated with more traditional recognition memory tasks. In a number of studies, younger and older adults have been shown photographs of younger and older faces, and a significant face age $\times$ age group interaction indicative of the own-age bias has been found. Of these studies, some showed evidence of a full crossover effect (e.g., Anastasi \& Rhodes, 2006; Bäckman, 1991; Perfect \& Moon, 2005), some showed enhanced performance with own-age faces only in younger adults (e.g., Bartlett \& Leslie, 1986; Lindholm, 2005; Mason, 1986; Wiese, Schweinberger, \& Hansen, 2008), and others reported it present only in older adults (e.g., Lamont, Stewart-Williams, \& Podd, 2005). An own-age bias for children (Anastasi \& Rhodes, 2005; Lindholm, 2005) has also been reported. Thus, previous research has demonstrated the existence of an own-age bias, but its exact nature and the underlying mechanisms that produce it remain unclear.

To explain the own-age bias, it may be useful to consider the wealth of existing research on the own-race bias. ${ }^{1}$ It is well documented that people are more accurate at recognizing faces of their own race than those of a different, less familiar race (see the review in Meissner \& Brigham, 2001).

The most popular explanation for this is the contact hypothesis. This proposes that people become experts at differentiating between faces of their own race due to increased contact with them, as compared with faces of 
other races (e.g., Brigham \& Malpass, 1985; Chiroro \& Valentine, 1995). A number of studies have shown a significant positive relationship between memory for faces of individuals from a certain race and the amount of contact the participant has had with that race (e.g., Slone, Brigham, \& Meissner, 2000; Wright, Boyd, \& Tredoux, 2003). Meissner and Brigham's (2001) meta-analysis also showed a significant, although small (accounting for approximately $2 \%$ of the variability in the data), relationship between other-race discrimination and self-report measures of interracial contact. However, it remains unclear precisely what aspect of contact is important for the development of an own-race bias to occur.

One class of explanations proposes that increased contact with a race (usually one's own) somehow produces improved perceptual processing for that particular facial group. For example, Rhodes, Tan, Brake, and Taylor (1989) suggested that exposure to own-race faces enhances people's ability to extract the configural information that is at the heart of expert face recognition (Diamond \& Carey, 1986). This explanation has been supported by demonstrations that other-race faces are processed less holistically (and hence, perhaps less efficiently) than own-race faces (e.g., Michel, Rossion, Han, Chung, \& Caldara, 2006; Rhodes et al., 1989; Tanaka, Kiefer, \& Bukach, 2004).

Another account based on perceptual processing is Valentine's (1991) multidimensional face space model. This suggests that faces are represented as points in a multidimensional space, whose dimensions consist of the facial characteristics that will best serve to discriminate between faces. It is thought that the dimensions develop in accordance with the individual's experience of faces. The ownrace bias is explained by suggesting that a lack of exposure to other-race faces means that the dimensions necessary for individuating them are less well represented than those needed to distinguish between own-race faces. Both of these theories assume that perceptual face-processing mechanisms become better tuned for the types of faces with which we have a greater amount of experience.

An alternative, although not mutually exclusive, class of explanations for the own-race bias focuses more on the social psychology of person recognition. These theories suggest that we automatically categorize faces according to whether or not they belong to our own in-group (e.g., our own race). This has consequences for how we subsequently process the face (e.g., Levin, 1996, 2000; Sporer, 2001). For example, Sporer's in-group/out-group model (IOM) suggests that in-group faces are encoded in an automatic, configural manner (typical of expert face processing), whereas out-group faces automatically trigger a categorization of that person as belonging to an outgroup. This categorization leads to the faces being $\operatorname{cog}$ nitively disregarded, resulting in a reduced, less efficient processing strategy and associated recognition deficits. Contact has a role to play in this process only insofar as it might help define the inclusion criteria of in-group and out-groups. ${ }^{2}$ This type of explanation could clearly be extended to explain recognition deficits for out-groups other than race, such as age and gender.
Yet another possibility is that contact per se does not affect face processing directly; instead, contact may reflect or drive the degree of interest a person has in faces of a particular kind and the resultant amount of attention allocated to them. It is this interest/attention that may be the important factor in determining how expert we are at processing faces of a particular category (e.g., own-age faces), and it may depend on the incentives for doing so (e.g., social rewards or punishments). This theory is admittedly speculative; however, Wright et al. (2003) found that although white and black university students had similar opportunities for experience with the opposite race, only the white students showed an own-race bias. Perhaps, due to the asymmetrical power relationships within South African society, the black students had an incentive for trying to recognize white faces, but the opposite was not true.

In the present study, we investigated the role of contact in the context of the own-age bias. Two groups were compared in terms of their ability to recognize children's faces and faces of their own age: trainee teachers, who had high occupational exposure to primary school children, together with a strong interest in them; and similarly aged controls, who had little exposure to children (or interest in them). By analogy with the explanations proposed for the own-race bias, we can make several competing predictions.

1. Improved perceptual processing explanations (e.g., Rhodes et al., 1989; Valentine, 1991) might predict that teachers and controls will perform similarly with both children's faces and adult faces. During their own development, both groups should presumably have had sufficient experience to become face experts with children's and adults' faces alike. Note that this prediction would be true only if one assumes that exposure to a certain class of face has enduring effects. If recent exposure to faces carries more weight than past experience, perceptual expertise explanations would predict that the controls should perform as well with adult faces as the trainee teachers did but worse with children's faces than the teachers did. We shall return to this point in the Discussion section.

2. Social categorization explanations (e.g., Levin, 1996, 2000; Sporer, 2001) predict that teachers and controls will be similar in performance; however, in this case, both groups should show better recognition for own-age faces, because the two groups of participants are the same age and children should constitute an out-group in both cases.

3. A third explanation is in terms of motivation to attend to faces (e.g., Wright et al., 2003). This would predict that teachers and controls will be similar in performance with adult faces, but not with children's faces: Because of trainee teachers' increased interest in, and attention to, children, they should be better than controls at recognizing children's faces.

\section{METHOD}

\section{Design}

A mixed design was used, with one between-subjects variable (group; two levels: trainee teachers and controls) and one repeated measures variable (age of person in photograph; two levels: child [8-11 years old] and own age [19-30 years old]). Measures of latency and accuracy $\left(d^{\prime}\right)$ were calculated. 


\section{Participants}

There were 66 participants in total: 33 in the trainee teacher group (mean age, 24.21 years; $S D, 2.46$; range, 21-30 years) and 33 controls (mean age, 22.94 years; $S D, 2.94$; range, 19-30 years). To ensure that contact was successfully operationalized into highand low-contact groups, the amount of occupational contact of the participants with 8- to 11-year-old children since leaving school was recorded. Controls had no contact of this type. Trainee teachers had a mean contact score of 16.50 months $(S D=17.05)$.

All the participants were University of Sussex students: undergraduates, postgraduates, or trainee teachers (students in a postgraduate Certificate of Education course).

\section{Materials}

Digital photographs were taken of 64 Caucasian males. Half were 8-11 years old, and half were $19-30$ years old. Two photographs were taken of each individual, one smiling and the other neutral. All the photographs were close-up, frontal face images without glasses, jewelry, facial hair, or other identifying features. Using Adobe Photoshop, each photograph was converted to grayscale and resized to $300 \times 350$ pixels. The picture's background and any information outside of the external face outline was removed (see Figure 1).

To ensure that the faces belonging to both age groups were similarly distinctive, 18 volunteers (age, 18-30 years old) rated each face on a 5 -point scale $(1=$ extremely distinctive, $5=$ not at all distinctive $)$. There was no significant difference in the distinctiveness ratings of the two groups of faces [paired samples $t(17)=0.23, p=.82, d=.05$ ]

\section{Procedure}

For the initial learning phase, the participants were shown 32 photographs ( 16 from each age group) in a random order at a 3 -sec rate, using SuperLab. A fixation cross was displayed in the center of the screen for $500 \mathrm{msec}$ before each face appeared. The participants were instructed to remember the faces as best they could, since they would later be asked to identify them. Following the learning phase, the participants completed a 3 -min filler task (the F-A-S verbal fluency task, in which participants are given $1 \mathrm{~min}$ per letter to name as many words as possible beginning with $\mathrm{F}, \mathrm{A}$, or S).

This was followed by the recognition test that consisted of 64 photographs, 32 of which had previously been seen in their alternate pose during the learning phase, and 32 of which were new. The photographs were counterbalanced for pose and old/new status and appeared in a different random order for each participant. The participants used the computer keyboard to indicate whether or not they recognized each face. Each face was preceded by a central fixation cross for $500 \mathrm{msec}$. Faces appeared individually, at a rate determined by the participant's speed of response. Each face remained on the screen until either a response was made or 2,500 msec had elapsed.

\section{RESULTS}

Since there was no effect of pose type on either accuracy or reaction time (RT), data were collapsed across this variable for the purpose of analysis.

\section{Accuracy}

Estimates of $d^{\prime}$ were used for analysis, rather than the percentage of correct responses: $d^{\prime}$ is a better index of recognition discriminability, since it takes into account false alarms (false recognition of distractor faces). Table 1 shows hit (correct identification of target faces) and false alarm rates. In calculating $d^{\prime}$, a flattening constant was used (as in Wright \& Sladden, 2003) so that $z$ scores could be calculated when the hit or false alarm rate was either 0 or 1 .

Figure 2 shows the mean $d^{\prime}$ scores for both experimental groups for the stimulus conditions (children and
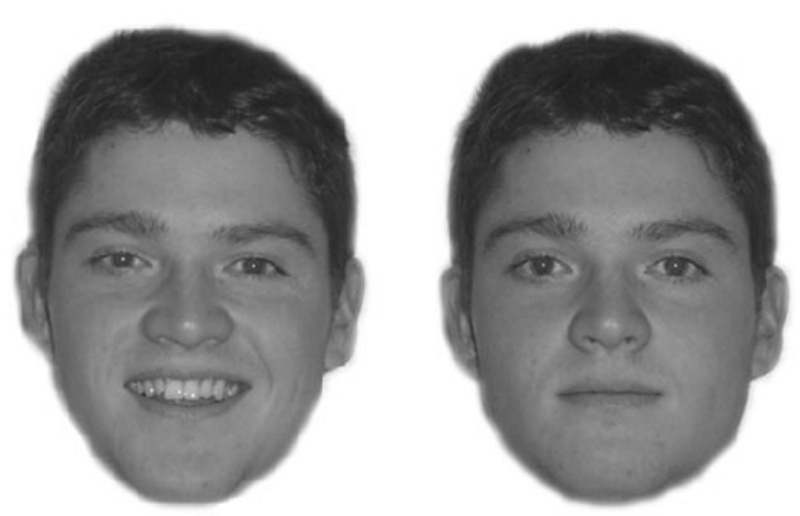

Figure 1. Examples of the facial stimuli used.

own-age photos). Both groups performed at above-chance levels $\left(d^{\prime}>0\right)$ throughout.

A two-way mixed ANOVA (two levels of group $\times$ two levels of face age) revealed that although there was no significant main effect of group $[F(1,64)=1.24, p=.27$, $\left.\eta_{\mathrm{p}}^{2}=.02\right]$ or face age $\left[F(1,64)=0.57, p=.45, \eta_{\mathrm{p}}^{2}=.01\right]$, there was a significant interaction between these two variables $\left[F(1,64)=7.70, p<.01, \eta_{\mathrm{p}}^{2}=.11\right]$, indicative of an own-age bias.

Follow-up paired $t$ tests ${ }^{3}$ demonstrated a significant effect of face age for the controls $[t(32)=2.04, p<.05$, $d=.50]$, showing an own-age bias in terms of accuracy. In contrast, the trainee teachers showed no such effect [trainee teachers, $t(32)=-2.00, p=.05, d=.27$ ], with a nonsignificant trend toward more accurately recognizing children's faces than faces of their own age group. Further independent $t$ tests revealed that trainee teachers were significantly more accurate than controls for children's faces $[t(64)=2.59, p<.01, d=.64]$, whereas the two groups performed similarly with faces of their own age $[t(64)=$ $-0.62, p=.54, d=-.15]$.

\section{Latency}

To minimize the variability often found in the RT data, each individual's performance was examined for every trial. Any RTs longer than the individual's mean \pm 2.5 standard deviations were replaced by that participant's mean RT (a method discussed in Ratcliff, 1993). In this way, $2.2 \%$ of the values for the trainee teachers and $2.4 \%$ for the control group were replaced. Corrected mean RTs are shown in Figure 2.

Table 1

Mean Proportion of Hits and False Alarms and $d^{\prime}$ Accuracy Scores

\begin{tabular}{|c|c|c|c|c|c|c|c|}
\hline \multirow{2}{*}{$\begin{array}{c}\text { Participant } \\
\text { Group }\end{array}$} & \multirow{2}{*}{$\begin{array}{c}\text { Photograph } \\
\text { Age }\end{array}$} & & & & & \multicolumn{2}{|c|}{$\begin{array}{c}\text { Accuracy } \\
\left(d^{\prime}\right)\end{array}$} \\
\hline & & $M$ & $S D$ & $M$ & $S D$ & $M$ & $S D$ \\
\hline Controls & Own age & .85 & .10 & .16 & .10 & 2.27 & 0.64 \\
\hline & Children & .78 & .11 & .16 & .11 & 1.95 & 0.64 \\
\hline Trainee teachers & Own age & .82 & .12 & .14 & .07 & 2.17 & 0.73 \\
\hline & Children & .85 & .09 & .13 & .08 & 2.35 & 0.61 \\
\hline
\end{tabular}



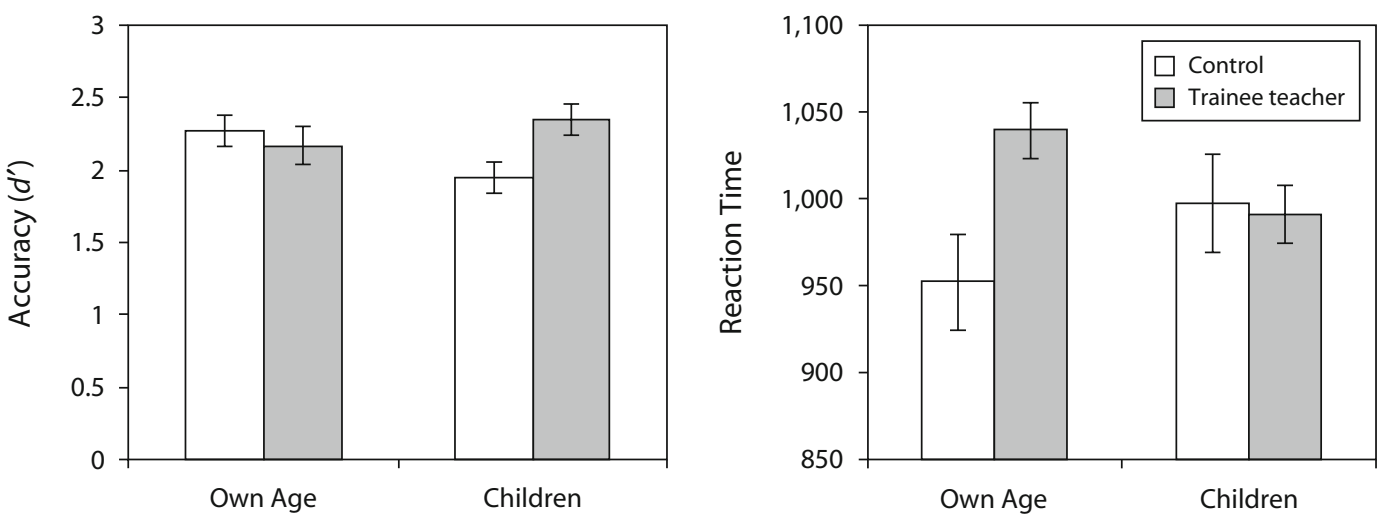

Figure 2. Mean accuracy scores and reaction times for both groups for the different facial stimuli (bars show the mean \pm one standard error).

Mean RTs for correct responses were entered into a mixed $2 \times 2$ ANOVA with group and face age as variables of interest. This revealed no significant main effect of group $\left[F(1,64)=1.61, p=.21, \eta_{\mathrm{p}}^{2}=.02\right]$ or face age $\left[F(1,64)=0.05, p=.83, \eta_{\mathrm{p}}^{2}<.01\right]$, but there was a significant interaction between these two variables $\left[F(1,64)=39.44, p<.001, \eta_{\mathrm{p}}^{2}=.38\right]$, indicative of an own-age bias.

Paired $t$ tests revealed a significant effect of face age for both experimental groups [trainee teachers, $t(32)=4.29$, $p<.001, d=.50$; controls, $t(32)=-4.64, p<.001$, $d=-.28]$ : Controls reacted more quickly for own-age faces, whereas trainee teachers responded more quickly to children's faces. Curiously, further independent $t$ tests revealed that both groups performed at similar speeds for children's faces $[t(64)=-0.19, p=.85, d=-.05]$, but controls were faster at responding to own-age faces $[t(64)=2.71, p<.01, d=.67]$. We have no explanation for why the controls were faster than the trainee teachers with own-age faces. However, in terms of the difference in speed of responding to own- and other-age faces, the results for the control group are consistent with an own-age bias, whereas those for the trainee teachers are not.

\section{DISCUSSION}

Previous research has suggested that we are better at recognizing faces of our own age group than those of a different age (e.g., Wright \& Stroud, 2002); however, the reasons for this remain unclear. Inspired by explanations of the own-race bias, the present study investigated the role of contact in the own-age bias in face recognition. Controls exhibited an own-age bias, in both accuracy and speed. In contrast, trainee teachers (who had high exposure to primary school children) showed no own-age bias; in fact, they were faster at recognizing children's faces than own-age faces and showed a trend toward being more accurate with children's faces.

Clearly, contact has a role to play in the own-age bias, but how exactly does it exert its effects? In the light of these results, let us reconsider the possible explanations for biases in face processing that were outlined earlier.
Improved perceptual processing explanations for the ownrace bias (e.g., Rhodes et al., 1989; Valentine, 1991) are viable explanations of the own-race bias. They could also explain demonstrations of an own-age bias by younger people trying to recognize older faces with which they have not yet had much experience (e.g., Wright \& Stroud, 2002). However, at first sight, they are unable to explain the own-age bias shown by the controls in the present study and the existence of own-age biases for all age groups (e.g., Anastasi \& Rhodes, 2005, 2006; Perfect \& Harris, 2003), because adults have presumably had ample opportunity to develop the most efficient mechanisms for processing faces younger than themselves when they themselves were young.

The improved perceptual processing class of explanation could explain own-age biases by older people for younger faces if one allows for the possibility that face representations are continually updated on a day-to-day, moment-tomoment basis. Facial adaptation studies (see the review in Clifford \& Rhodes, 2005) show that recent exposure can markedly affect our subsequent perception of faces. This might explain why adults find it harder to recognize children's faces: Current experience with adult faces, and correspondingly less experience with children's faces, could lead to perceptual tuning that is optimized for the former. Such an explanation could account for the trainee teachers' enhanced performance with children's faces, because they have had more recent experience with them.

However, there is also evidence against perceptual expertise explanations: Perfect and Moon (2005) investigated whether the own-age bias would be affected by inverting faces (a manipulation known to disrupt configural processing; e.g., Diamond \& Carey, 1986). If the own-age bias is the result of more efficient configural processing due to increased expertise, one would expect to see a larger inversion deficit for own-age faces. This, however, was not the case, implying that a configural-expertise account of the own-age bias may not be appropriate.

The second type of explanation that was outlined in the introduction was in terms of social categorization: that in-group faces are processed more deeply, and hence efficiently, than out-group faces (e.g., Levin, 1996, 2000; 
Sporer, 2001). Again, this type of theory can account for the own-race bias; but it is clear that theories based solely on concepts of differential processing of in-group and outgroup faces are not supported by the present findings. Particularly problematic for Sporer's IOM is the finding that trainee teachers performed better with children's faces (an out-group) than with faces of their own age group (their in-group). The only way that the IOM could explain these results is if the children's faces, which are clearly important to the trainee teachers, were being categorized by them as in-group. This seems unlikely, since the inclusion of people into one's in-group is usually based on selfreferential information and shared characteristics that are deemed socially important (as has been suggested by List, 1986). Clearly, since this study has shown that exposure is important and self-referent age information is not, as currently formulated the IOM is not a plausible explanation of the own-age bias.

The third explanation outlined in the introduction emphasized the importance of motivation to attend to faces. This theory can successfully account for the present results (and explain the own-race bias; see Wright et al., 2003), correctly predicting that teachers and controls would be similar in accuracy with adult faces, but not with children's faces. As compared with the controls, the trainee teachers have higher exposure to children's faces on a day-to-day basis. However, it is also likely that they have higher motivation to distinguish between these faces, due to their occupational demands, and thus are likely to attend to them to a greater extent. More generally, motivation is likely to be a factor in the normally observed own-age bias, perhaps due to the social rewards and punishments associated with being able to effectively (or not) distinguish between and recognize people belonging to one's own age group. Thus, the data could support an explanation of the own-age bias in terms of motivation and interest for the faces.

In summary, our findings suggest that contact plays an important role in mediating the own-age bias in face recognition. At present, it is difficult to choose between a perceptual expertise explanation (if expertise is not maintained in the absence of exposure) and a motivational account. One way to do this would be to manipulate motivation and current exposure independently; research is currently in progress to do this. Further research could also investigate how manipulations of configural/holistic information affect the processing of faces of different ages. This would provide further insight into the possible role of perceptual expertise in the own-age bias.

\section{AUTHOR NOTE}

We are very grateful to Elinor McKone, Tim Perfect, and an anonymous reviewer for their extremely helpful and constructive comments on an earlier draft of the manuscript. In particular, we thank Elinor McKone for her clear-sighted analysis of the mechanisms by which contact could influence face recognition. Correspondence concerning this article should be addressed to V. Harrison, Department of Psychology, School of Life Sciences, Falmer, Brighton BN1 9QH, England (e-mail: vmh20@sussex.ac.uk).

\section{REFERENCES}

Adams-Price, C. (1992). Eyewitness memory and aging: Predictors of accuracy in recall and person recognition. Psychology \& Aging, 7, 602-608

Anastasi, J. S., \& Rhodes, M. G. (2005). An own-age bias in face recognition for children and older adults. Psychonomic Bulletin \& Review, 12, 1043-1047.

Anastasi, J. S., \& Rhodes, M. G. (2006). Evidence for an own-age bias in face recognition. North American Journal of Psychology, $\mathbf{8}$, 237-252.

BäCKMAN, L. (1991). Recognition memory across the adult life span: The role of prior knowledge. Memory \& Cognition, 19, 63-71.

Bartlett, J. C., \& Leslie, J. E. (1986). Aging and memory for faces versus single views of faces. Memory \& Cognition, 14, 371-381.

Brigham, J. C., \& Malpass, R. S. (1985). The role of experience and contact in the recognition of faces of own- and other-race persons. Journal of Social Issues, 41, 139-155.

Chiroro, P., \& Valentine, T. (1995). An investigation of the contact hypothesis of the own-race bias in face recognition. Quarterly Journal of Experimental Psychology, 48A, 879-894.

Clifford, C. W. G., \& Rhodes, G. (Eds.) (2005). Fitting the mind to the world: Adaptation and after-effects in high-level vision. Oxford: Oxford University Press.

DiAMOND, R., \& CAREY, S. (1986). Why faces are and are not special: An effect of expertise. Journal of Experimental Psychology: General, 115, 107-117.

Fulton, A., \& Bartlett, J. C. (1991). Young and old faces in young and old heads: The factor of age in face recognition. Psychology \& Aging, 6, 623-630.

HedDEN, T., \& GABRIELI, J. D. E. (2004). Insights into the ageing mind: A view from cognitive neuroscience. Nature Reviews Neuroscience, $\mathbf{5}, 87-96$

Lamont, A. C., Stewart-Williams, S., \& Podd, J. (2005). Face recognition and aging: Effects of target age and memory load. Memory \& Cognition, 33, 1017-1024.

LEvin, D. T. (1996). Classifying faces by race: The structure of face categories. Journal of Experimental Psychology: Learning, Memory, \& Cognition, 22, 1364-1382.

LEvin, D. T. (2000). Race as a visual feature: Using visual search and perceptual discrimination tasks to understand face categories and the cross-race recognition deficit. Journal of Experimental Psychology: General, 129, 559-574.

LindHOLM, T. (2005). Own-age biases in verbal person memory. Memory, 13, 21-30.

LisT, J. A. (1986). Age and schematic differences in the reliability of eyewitness testimony. Developmental Psychology, 22, 50-57.

MASON, S. E. (1986). Age and gender as factors in facial recognition and identification. Experimental Aging Research, 12, 151-154.

Meissner, C. A., \& Brigham, J. C. (2001). Thirty years of investigating the own-race bias in memory for faces: A meta-analytic review. Psychology, Public Policy, \& Law, 7, 3-35.

Michel, C., Rossion, B., Han, J., Chung, C.-S., \& Caldara, R. (2006). Holistic processing is finely tuned for faces of one's own race. Psychological Science, 17, 608-615.

Perfect, T. J., \& Harris, L. J. (2003). Adult age differences in unconscious transference: Source confusion or identity blending? Memory \& Cognition, 31, 570-580.

Perfect, T. J., \& Moon, H. C. (2005). The own-age effect in face recognition. In J. Duncan, L. Phillips, \& P. McLeod (Eds.), Measuring the mind: Speed, control and age (pp. 317-340). Oxford: Oxford University Press.

RatcLIFF, R. (1993). Methods for dealing with reaction time outliers. Psychological Bulletin, 114, 510-532.

Rhodes, G., Tan, S., Brake, S., \& TAYlor, K. (1989). Expertise and configural coding in face recognition. British Journal of Psychology, 80, 313-331.

Searcy, J. H., Bartlett, J. C., \& Memon, A. (1999). Age differences in accuracy and choosing in eyewitness identification and face recognition. Memory \& Cognition, 27, 538-552.

Searcy, J. H., Bartlett, J. C., Memon, A., \& Swanson, K. (2001). 
Aging and lineup performance at long retention intervals: Effects of metamemory and context reinstatement. Journal of Applied Psychology, 86, 207-214.

Slone, A. E., Brigham, J. C., \& Meissner, C. A. (2000). Social and cognitive factors affecting the own-race bias in Whites. Basic \& Applied Social Psychology, 22, 71-84.

SPORER, S. L. (2001). Recognizing faces of other ethnic groups: An integration of theories. Psychology, Public Policy, \& Law, 7, 36-97.

Tanaka, J. W., Kiefer, M., \& BuKach, C. M. (2004). A holistic account of the own-race effect in face recognition: Evidence from a crosscultural study. Cognition, 93, B1-B9.

Valentine, T. (1991). A unified account of the effects of distinctiveness, inversion, and race in face recognition. Quarterly Journal of Experimental Psychology, 43A, 161-204.

Wiese, H., Schweinberger, S. R., \& Hansen, K. (2008). The age of the beholder: ERP evidence of an own-age bias in face memory. Neuropsychologia, 46, 2973-2985.

Wright, D. B., Boyd, C. E., \& Tredoux, C. G. (2003). Inter-racial contact and the own-race bias for face recognition in South Africa and England. Applied Cognitive Psychology, 17, 365-373.

Wright, D. B., \& SLADDEN, B. (2003). An own gender bias and the importance of hair in face recognition. Acta Psychologica, 114, 101-114.
Wright, D. B., \& Stroud, J. N. (2002). Age differences in lineup identification accuracy: People are better with their own age. Law \& Human Behavior, 26, 641-654.

YARMEY, A. D. (1993). Adult age and gender differences in eyewitness recall in field settings. Journal of Applied Social Psychology, 23, 1921-1932.

\section{NOTES}

1. The own-age, own-race, and own-gender (Wright \& Sladden, 2003) biases may or may not be analogous phenomena, especially considering the distinctive feature of the own-age bias: that a person could have belonged to other age group(s) before, in a way not possible with race or sex. But the theories put forward to explain the own-race bias make a useful starting point for this type of research.

2. Note that the quality of contact, rather than merely the amount of contact, might be the important variable here; see Wright et al. (2003) for a demonstration of this in the context of the own-race bias.

3. All $t$ tests reported in the Results section are two-tailed tests.

(Manuscript received November 16, 2007; revision accepted for publication September 25, 2008.) 